\title{
Learning from low income countries: mental health
}

Kwame McKenzie, Vikram Patel, Ricardo Araya

Organising mental health services to harness the support of the family and community may improve outcomes

Royal Free and University College Medical School and Barnet, Enfield and Haringey Mental Health NHS Trust, Department of Mental Health Sciences, London NW3 2PF

Kwame McKenzie senior lecturer in psychiatry

London School of Hygiene and Tropical Medicine, London

WC1E 7HT

Vikram Patel

reader in

international mental

health

Division of

Psychiatry, Cotham

House, Bristol

BS6 6JL

Ricardo Araya

reader

Correspondence to:

K McKenzie

k.mckenzie@

rfc.ucl.ac.uk

BMJ 2004;329:1138-41
Thirty one per cent of all years lived with disability are due to mental illness. Mental health problems are important in every country, even those with high burdens of illness due to infectious diseases. ${ }^{1}$

Wealthy countries generally have more services to combat mental health problems than low income countries. In many low income countries there is typically one psychiatrist per population of 1000000 , with little or no multidisciplinary team and few regular drugs. Given this mismatch, it is easy to conclude that there is little that psychiatry in developed countries can learn from poorer countries, but this is not the case.

Services in low income countries are often greatly under-resourced, under strain, and leave most people with mental health problems with no care. But there are examples of different ways to treat or prevent mental illness from which high income countries can learn. Some are born from the ingenuity of necessity, others from cultural knowledge. ${ }^{2-6}$

We do not aim to idealise low income countries, to demonise high technology and psychiatric care, or to offer the stereotype of cohesive traditional communities as a panacea, which could undermine the development of appropriate services. We simply present examples that challenge the orthodox, make us pause to think, and offer rational models for provision of care that high income countries may consider useful

\section{The pathways to care and prevention}

The figure shows a pathway through care for someone in psychological distress. This illustrates the variety of levels at which the cited interventions work.

\section{Prevention of mental illness by social support}

Pathways to care in high income countries usually neglect community services and factors in operation before statutory care is sought. The development of provision of traditional care is an area where high income countries can learn from lower income countries. Although traditional care often reflects a lack of resources rather than an active choice, medical care does not always produce better outcomes. An example is the prevention of postpartum depression, which occurs in 10-20\% of women in the United Kingdom and United States but is considered rare in Chinese populations, Fiji, and some African populations. ${ }^{3}$ Postpartum depression has an important effect on the mother's occupational and social function, bonding with her child, suicide, homicide, and burden on the family. Social support is considered important in prevention. ${ }^{3}$

Structured social supports after childbirth are described in groups of women with low rates of postpartum depression. ${ }^{3}$ In traditional Chinese society, women's bodies are considered weak in the month

\section{Summary points}

Wealthy countries can learn from prevention and management strategies for mental health problems in low income countries

Efficacy and quality, not just cost, should be regarded as the important factors in choosing initiatives

Increased community responsibility and diversification of the agents who supply care should not be used to decrease spending on healthcare

after childbirth, and the mothers are prohibited from working and visiting. Extra help is brought in-often it is the woman's mother or mother in law who helps with domestic duties, looks after the family, and offers advice. ${ }^{3}$ Studies in Hong Kong show lower levels of depression at three months in women who have this support. ${ }^{3}$ The rate of depression seems, however, to depend on who offers the support and whether this leads to conflict with the mother. ${ }^{4}$

In Fiji, new mothers are given intensive social supports and mandated relief from domestic duties (3-4 months) and work on family farms (12 months). ${ }^{3}$ In addition, a close female family member assists with the care of the newborn and other infants. The local community prepares food for the household. This support has also been linked to lower rates of postpartum depression. ${ }^{3}$

It would be hard, intuitively, not to come to the conclusion that traditional support offers benefit, but better evidence may be required by high income countries. Perhaps the central message is that external care should be focused on the mother, not the baby. Increasing care for new mothers would not require huge cultural changes. A study in the UK's West Midlands health region found a significantly decreased rate of postpartum depression when care was redesigned to focus on the needs of the mother. ${ }^{5}$

The response does not have to be service led. Governments could increase the pool of social support available to mothers. Perhaps paid leave from work to support mothers could be extended to grandparents or family members outside the nuclear family. Rich countries could consider longer periods of maternity leave and changes in financial packages to decrease the economic pressures to return to work.

The aim is not to transfer social responsibilities from the state to families and communities but to share the wealth of a nation to facilitate social support and give mothers and their families a safer financial environment in which to make choices. Given the eco- 


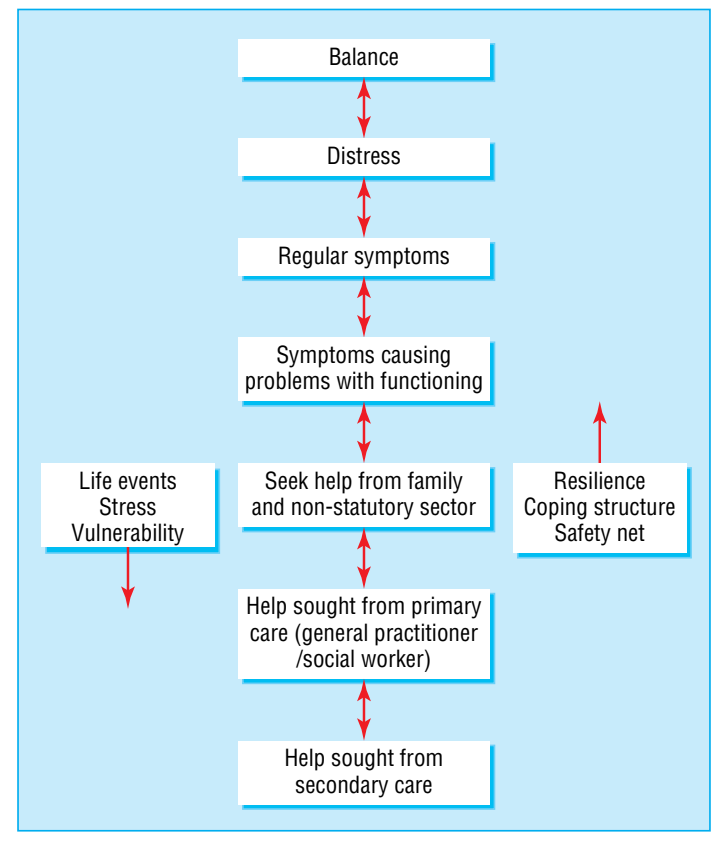

Pathway through care for someone in psychological distress

nomic and social impact of postnatal depression, with little evidence that current strategies decrease the rates of illness, employing some of the remedies from traditional paradigms may be cost effective.

\section{Primary care response to depression}

Worldwide, depression is one of the four main causes of life years lost to illness and the main non-fatal cause of disease. ${ }^{6}$ Care for depression in many developed countries is poorly coordinated and so often ineffective. Depression is commonly managed by primary care physicians, who have variable knowledge and interest in dealing with it. Many doctors who treat depression have no formal postgraduate training in psychiatry. Patients from the poorer areas of rich countries are less likely to receive effective treatment.

Structured models that aim to provide acceptable, simple, low cost but effective treatment for depression have emerged from low income countries. For instance, a recent randomised controlled trial in Santiago, Chile, reported on an effective, coordinated stepped care approach to treating depression. ${ }^{7}$ This multicomponent intervention was led by a non-medical health worker and included group psychoeducation about depression, systematic monitoring of symptoms, and a structured drug programme for those with more severe or persistent depression. At six months, $70 \%$ of the stepped care group had recovered. This study, and others in the developed world, have shown that small investments in the treatment of depression can have a huge impact, especially in socially deprived populations. ${ }^{8}$ This message has influenced decision makers, and the stepped care approach is now used to treat depression in primary care in Chile. ${ }^{9}$

The structured approach facilitated an increased role for non-medical staff and patients. One of the outcomes of the programme was greater patient involvement, and in some places women's groups started by the programme were still functioning after two years. The outcomes would be considered good for many inner city areas in high income countries. Clearly, however, the development of structured programmes may be easier in places where there are fewer services and vested interests.

\section{Secondary care in non-traditional settings}

Jamaica has developed innovative responses to the burden of care of those with severe mental illness. One innovation has been to treat people with psychiatric problems on acute general hospital wards. ${ }^{10}$ The rationale was that if acute psychosis and other presentations of mental distress were emergencies then clinicians on medical wards should play their part. Those admitted to the ward rather than a psychiatric hospital had a shorter hospital stay and better compliance with treatment, leading to employment. As this was a naturalistic study, the results should be treated with caution.

\section{From secondary care to community care}

India has developed the community based rehabilitation model. This comprises three tiers in which outpatient care (first tier) is supplemented with help from community case workers (second tier) and community rehabilitation initiatives (third tier). ${ }^{11}$ Case workers are drawn from the populations they are going to serve, and offer a service to users, their families, and communities. Initiatives are planned in a forum called a village health group, which includes carers and key local stakeholders. Compared with outpatient treatment, the community based rehabilitation model leads to better outcomes for disability, compliance, and engagement with treatment. ${ }^{11}$ The development of local health groups that focus on rehabilitation could offer a model to help deal with stigma, social exclusion, and community involvement.

\section{Conclusion}

We have provided some examples at different levels of the pathway to care and prevention of mental illness where the developed world could learn from the developing world. High income countries considering such developments would have to make them fit for purpose in a different social and economic environment. The issue of sustainability also arises. Community based support after childbirth has a long history, and medical ward care for psychiatric emergencies in Jamaica has been used for 30 years, but

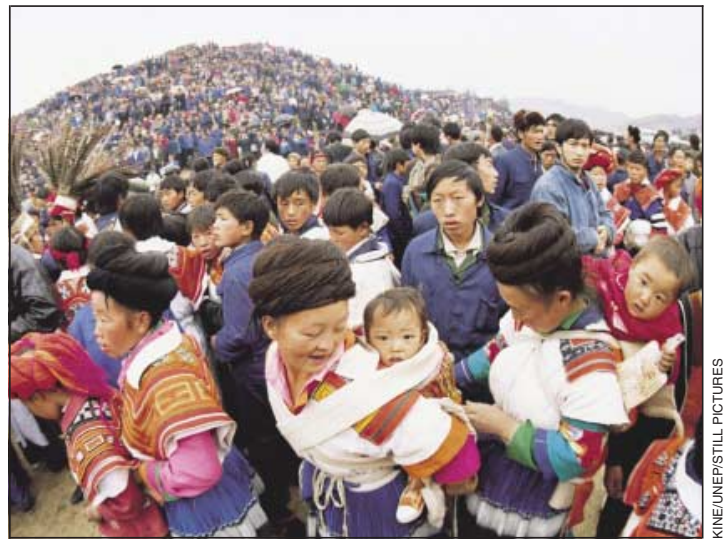

Social support after childbirth is linked with low rates of postpartum depression 
the stepped care approach and community based rehabilitation model are relatively new initiatives.

It could be argued that all these models use the least possible healthcare resources. With fewer resources the community may be empowered to take on more responsibilities for ill people. Some may see this as a positive development, but others may see such initiatives as a way of transferring state responsibilities to the population. If there were to be such a diversification in provision of care in the developed world then it would be hoped that resources would follow responsibility.

The development of sufficient open access psychotherapeutic groups for depression as part of a stepped care approach, or the changes in tax and benefits required for increased support to new mothers, may only be cost neutral if they are balanced against the costs of poorly or untreated depression. If these initiatives represented a decrease in service quality or outcome, it would be difficult for developed countries to consider them.

In the developing world the poorest have no choice but to take what is offered. This is sometimes true of inner city areas in developed countries where novel cheaper healthcare initiatives are sometimes introduced. We understand the tension between value for money, innovation, and quality. We do not advocate the development of two tier healthcare systems in developed countries.

Of interest for developed countries is that when these simple models have been tested in the developing world they have been shown to be at least equally effective as more sophisticated and expensive ones. Moreover, whether through decreasing the cultural gulf between services and their recipients, increasing community involvement in health care, reinforcing preventive strategies, or developing more rational models of service delivery the examples that we have cited may offer added value.

Contributors: All authors contributed to the design, the writing, and the editing of this article. KMcK produced the first draft, taking into account the coauthors' comments.

Funding: KMcK and RA were supported by their universities. VP is supported by a Wellcome Trust career development fellowship in clinical tropical medicine.

Competing interest: None declared.

1 World Health Organization. The world health report 2001. Mental health: New understanding, new hope. Geneva: WHO, 2001.

Kleinman A Cohen A World mental health problems and priorities in low income countries. New York: Oxford University Press, 1995.

Becker AE, Lee DTS. Indigenous models for attenuation of post partum depression: case studies from Fiji and Hong Kong. In: Cohen A Kleinman A, Saraceno B, eds. World mental health casebook. New York: Kluwer, 2002

4 Lee DTS, Yip ASK, Leung TYS, Chung TKH. Ethnoepidemiology of postnatal depression: prospective multivariate study of sociocultural risk factors in a Chinese population in Hong Kong. Br J Psychiatry 2004;184:34-40.

5 MacArthur C, Winter HR, Bick DE, Lilford RJ, Lancashire RJ, Knowles H, et al. Re-designing postnatal care: a randomized controlled trial of protocol based midwifery-led care focused on individual women's physical and col based midwery-led are foctur on individual wom

U Usyün TB, Ayuso-Mateos JL, Chatterji S, Mathers C, Murray JL. Global burden of depressive disorders in the year 2000. Br J Psychiatry burden of depresit

7 Araya R, Rojas G, Fritsch R, Gaete J, Rojas M, Simon G, et al. Treating depression in primary care in low income women in Santiago, Chile: a randomized controlled trial. Lancet 2003;361:995-1000.

8 Wells K, Sherbourne C, Schoenbaum M, Ettner S, Duan N, Miranda J, et al. Five-year impact of quality improvement for depression: results of a group-level randomized controlled trial. Arch Gen Psychiatry 2004:61: 378-86.

9 Guia Clinica para la Atencion Primaria: La Depresion: Deteccion, Diagnostico y Tratamiento. Programa de diagnostico y tratamiento integral de la depression en la atencion primaria. Santiago, Chile: Ministry of Health, 2009.

10 Hickling FW, McCallum M, Nooks L, Rodgers-Johnson P. Treatment of acute schizophrenia in open general medical wards in Jamaica. Psychiatr Serv 2000;51:659-63.

11 Chatterjee S, Patel V, Chatterjee A, Weiss H. Evaluation of a communitybased rehabilitation model for chronic schizophrenia in rural India. $\mathrm{Br}$ Psychiatry 2003;182:57-62.

\title{
Commentary: Community models of mental care warrant more governmental support
}

\author{
Malcolm W Battersby
}

Flinders Human Behaviour and Health Research Unit, Flinders University, Bedford Park, 5042, SA

Australia

Malcolm W Battersby senior lecturer in psychiatry

malcolm.battersby@ flinders.edu.au
Although developed countries are relatively well resourced there is an unmet demand for mental health services, particularly for anxiety disorders and depression. A similar and escalating demand exists for services for other forms of chronic illness too, such as diabetes secondary to obesity. In both, the potential of community care is increasingly recognised.

The core elements that emerge from the models McKenzie et al describe are community involvement in the planning and delivery of services, harnessing social support, and providers with a diversity of skill levels in stepped services. ${ }^{1}$ Replicating these models in wealthy countries would require overcoming considerable barriers in the form of system inertia, multiple funders, funding that creates disincentives to provide alternative services, professional vested interests and boundaries, stigma, loss of the sense of community, breakdown of the family, and lack of resources for the treatment and prevention of mental disorders compared with medical conditions.

But there are examples of services in developed countries that have overcome some of these barriers. The use of collaboratives as a large scale method of bringing about change in the delivery of services for chronic illness have been widely used in the United States, United Kingdom, and Canada and, more, recently Australia. ${ }^{2 \mathrm{w} 1}$ These collaboratives base their programme for change on the six elements of the chronic care model, ${ }^{3}$ one of which is support for self management. Although these programmes have improved health outcomes, they have focused on diabetes and heart failure rather than on mental illness. ${ }^{\mathrm{w} 2 \mathrm{w4}}$

The UK collaborative on falls prevention, which relies almost entirely on teams of community

\section{References w1-w9 are on bmj.com}

